\title{
Site-Specific Solar Resource Measurements for Industrial Solar Applications
}

William Marion

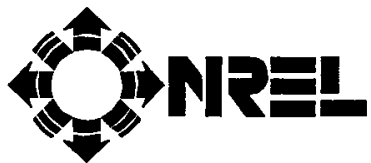

National Renewable Energy Laboratory 1617 Cole Boulevard Golden, Colorado 80401-3393 A national laboratory operated for the U.S. Department of Energy under contract No. DE-AC02-83CH10093

Prepared under Task No. SI414010

June 1994 


\section{NOTICE}

NOTICE: This report was prepared as an account of work sponsored by an agency of the United States government. Neither the United States government nor any agency thereof, nor any of their employees, makes any warranty, express or implied, or assumes any legal liability or responsibility for the accuracy, completeness, or usefulness of any information, apparatus, product, or process disclosed, or represents that its use would not infringe privately owned rights. Reference herein to any specific commercial product, process, or service by trade name, trademark, manufacturer, or otherwise does not necessarily constitute or imply its endorsement, recommendation, or favoring by the United States government or any agency thereof. The views and opinions of authors expressed herein do not necessarily state or reflect those of the United States government or any agency thereof.

Printed in the United States of America Available from:

National Technical Information Service

U.S. Department of Commerce

5285 Port Royal Road

Springfield, VA 22161

Price: Microfiche A01

Printed Copy $\mathrm{AO} 3$

Codes are used for pricing all publications. The code is determined by the number of pages in the publication. Information pertaining to the pricing codes can be found in the current issue of the following publications which are generally available in most libraries: Energy Research Abstracts (ERA); Government Reports Announcements and Index (GRA and I): Scientific and Technical Abstract Reports (STAR); and publication NTIS-PR-360 available from NTIS at the above address. 


\section{Preface}

This work was performed by the National Renewable Energy Laboratory's (NREL's) Analytic Studies Division under the Solar Process Heat Task within the Solar Industrial Program. It describes NREL's assistance to industry through the Solar Industrial Program in measuring the solar radiation resource at specific locations. The assistance is primarily in the form of equipment loans and data collection and analysis. The author would like to acknowledge NREL staff members Dave Renné and Tom Stoffel for their contributions to the report and their review.

Approved for the

National Renewable Energy Laboratory

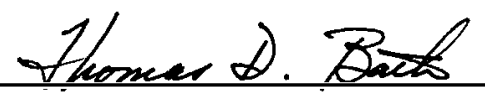

Thomas Bath, Director Analytic Studies Division

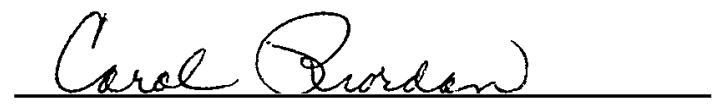

Carol Riordan, Manager

Technology \& Resource Assessment Branch

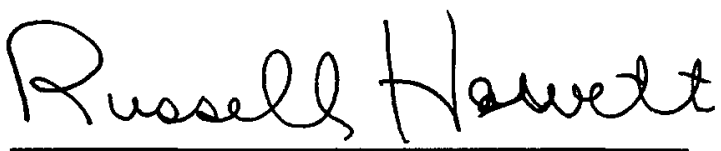

Russell Hewett, Task Leader

Solar Process Heat Task

Thermal Systems Branch 


\section{Table of Contents}

$$
\text { Page }
$$

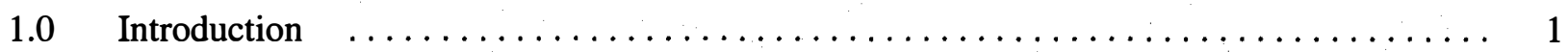

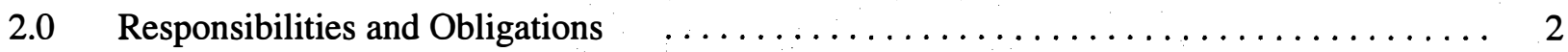

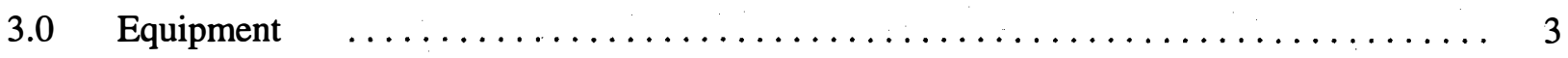

4.0 Data Quality Assessment $\quad \ldots \ldots \ldots \ldots \ldots \ldots \ldots \ldots \ldots \ldots \ldots \ldots \ldots \ldots \ldots \ldots$

$5.0 \quad$ Data and Summary Information $\quad \ldots \ldots \ldots \ldots \ldots \ldots \ldots \ldots \ldots \ldots \ldots \ldots \ldots$

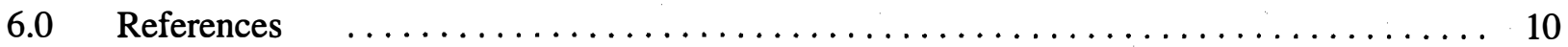

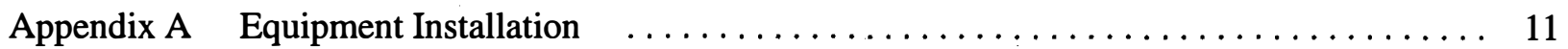

Appendix B Sample Maintenance \& Operation Log Sheet $\quad \ldots \ldots \ldots \ldots \ldots \ldots \ldots \ldots$ 


\section{List of Figures}

Page

1. SERI QC data boundaries for two-element quality assessment $\quad \ldots \ldots \ldots \ldots \ldots \ldots \ldots \ldots$

2. Sample format of data file SACR9403.QAD $\quad \ldots \ldots \ldots \ldots \ldots \ldots \ldots \ldots \ldots \ldots \ldots$

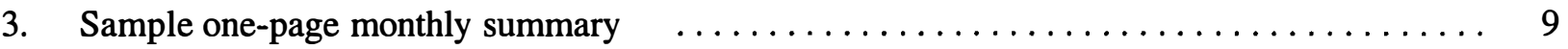

\section{List of Tables}

1. Flagging Convention for Global Horizontal, Diffuse Horizontal,

2. Flagging Convention for Dry-Bulb Temperature 


\subsection{Introduction}

As part of the National Renewable Energy Laboratory's (NREL's) Solar Industrial Program, NREL loans equipment for measuring solar radiation to qualified parties. The purpose of the program is to provide assistance in quantifying the solar radiation resource at prospective sites to reduce the risks of deploying industrial solar energy systems.

The solar radiation measurements permit comparisons to verify existing data bases and provide a source of data based on measurements, instead of less accurate models. The assistance is primarily in the form of equipment loans and data collection and analysis; no exchange of funds occurs. The period of data collection for a site is approximately 1 year, or perhaps longer depending on equipment availability. Organizations interested in participating in this program may contact Russell Hewett or William Marion at NREL to discuss equipment availability and their eligibility.

This report outlines the responsibilities and obligations of NREL and the solar industry participant. It also describes the equipment for measuring solar radiation, the data quality assessment procedures, and the format of the data and the summary reports provided to the industry participant. 


\subsection{Responsibilities and Obligations}

Both NREL and the solar industry participant have responsibilities and obligations to ensure the success of the program. For NREL, the responsibilities and obligations are to:

- Determine that the need for solar resource information cannot be met with existing data.

- Provide equipment (with current calibration) and installation instructions.

- Retrieve data over telephone lines.

- Quality assess the data and provide hourly data and monthly summaries to the solar industry participant.

- Archive the data for future applications; NREL may distribute the data freely.

For the solar industry participant, the responsibilities and obligations are to:

- Provide a site description that includes latitude, longitude, elevation, and field-of-view of the sky. Photographs are recommended.

- Install a dedicated telephone line for the datalogger and provide the telephone number to NREL. Installation costs and monthly telephone service charges at the site are paid for by the solar industry participant.

- Install and operate the equipment and perform maintenance and repairs per NREL's instructions.

- Provide appropriate site security.

- Remove and return the equipment at NREL's request. 


\subsection{Equipment}

NREL provides a rotating shadowband pyranometer system manufactured by Ascension Technology, Inc. (ATI), Waltham, Massachusetts. The system includes a datalogger, a telephone modem, and a photovoltaic (PV) power supply. The PV power supply provides electric power to the equipment so that electric utility service is not necessary. As programmed, the system records hourly averages of global horizontal radiation, diffuse horizontal radiation, direct normal radiation, and dry-bulb temperature.

The rotating shadowband pyranometer system measures both global and diffuse horizontal solar radiation using a single sensor. Once each minute, the shadowband rotates over the sensor and shades the sensor from direct normal radiation while diffuse radiation is measured. When unshaded, the sensor measures global horizontal solar radiation. The following equation calculates direct normal radiation from the relationship:

$$
\text { global }=\text { diffuse }+(\text { cosine of the solar zenith angle }) \mathrm{x} \text { direct normal. }
$$

The solar zenith angle is computed based on the date, time of measurement, and geographic location.

In 1992, NREL completed tests of the rotating shadowband pyranometer system and found it to be reliable with a measurement uncertainty for direct normal radiation of about $6.5 \%$ (Stoffel, Riordan, and Bigger 1992). Direct normal measurements with a pyrheliometer mounted on a tracker have a lower measurement uncertainty (about $2 \%$ ), but require more operator attention to keep the tracker operating properly. When determining solar radiation over time, such as monthly averages, even small losses in data resulting from misaligned trackers may significantly increase the uncertainty of the monthly average. Consequently, system reliability and operator involvement was an important consideration when selecting the equipment for this measurement program.

For ease of installation, the rotating shadowband pyranometer system is designed to be attached to a metal post secured to the roof or wall of a building. ATI has provided instructions for installation procedures and requirements. NREL clarified the instructions and provided additional information pertinent to this program. Appendix A of this report contains the installation instructions.

The industry participant can ensure proper equipment operation and sensor cleanliness by performing equipment maintenance on site. This normally takes just a few minutes two or three times a week. Appendix B contains a sample maintenance and operation log sheet used to record maintenance activities. The log sheet also provides data users with a means to judge whether the station was well maintained. 


\subsection{Data Quality Assessment}

After data are collected, quality assessment can be performed to indicate whether a data value is reasonable, too small, too large, or missing. It is not used to change data values, and should not be confused with quality control and quality assurance. Quality control and quality assurance occur before and during data collection and include procedures such as the proper selection and installation of instruments and data acquisition equipment, and regular maintenance and calibration. Quality assessment cannot replace quality control and quality assurance because it will not detect small changes caused by dirty or unleveled sensors or changes in calibration factors.

Quality assessment procedures for the solar radiation and dry-bulb temperature data assign a flag ranging from 0 to 99 to each of the hourly data elements. To select data for analysis purposes, the flags may be used to screen the data files for data meeting user-defined acceptance criteria.

\subsection{Quality Assessment for Solar Radiation Data}

The three solar radiation data elements-global horizontal, diffuse horizontal, and direct normal-are quality assessed using SERI QC, a procedural and software package developed by NREL (1993). SERI QC defines ranges of acceptable data, depending on whether one, two, or all three hourly data elements are present. Ranges are defined based on dimensionless parameters normalized with respect to extraterrestrial radiation, where:

$$
\begin{aligned}
\mathrm{K}_{\mathrm{t}} & =\text { Clearness index or global horizontal transmittance } \\
& =\text { Global horizontal radiation } \div \text { extraterrestrial horizontal radiation } \\
\mathrm{K}_{\mathrm{d}} & =\text { Diffuse horizontal transmittance } \\
& =\text { Diffuse horizontal radiation } \div \text { extraterrestrial horizontal radiation } \\
\mathrm{K}_{\mathrm{n}} & =\text { Direct normal transmittance. } \\
& =\text { Direct normal radiation } \div \text { extraterrestrial direct normal radiation. }
\end{aligned}
$$

Depending on the circumstances, SERI QC performs one-element, two-element, or three-element tests. First, it performs a one-element test by defining a range of acceptable values between minimum and maximum values of $\mathrm{K}_{\mathrm{t}}, \mathrm{K}_{\mathrm{d}}$, or $\mathrm{K}_{\mathrm{n}}$, depending on the element being tested, based on three air mass regimes and the month of the year.

Second, if the zenith angle (at the middle of the hour) is less than or equal to $80^{\circ}$, and all three of the elements are present, SERI QC performs a three-element test by defining a range of acceptable values so that the equation $K_{t}=K_{d}+K_{n}$ is satisfied within an arbitrary error limit of \pm 0.03 , which accounts for measurement uncertainties.

Third, if the data pass the three-element test (or only two elements passed the one-element test), SERI QC performs a two-element test by defining a range of acceptable values within boundaries such as those shown in Figure 1. The boundaries in the figure are normally determined empirically for three different air mass regimes for each month using data collected at the site. Because there may be no historical data for a new measurement site, we use boundaries previously established for nearby measurement stations. These boundaries are for nearby stations listed in the 1961-1990 National Solar Radiation Data Base (NSRDB--Vol. 1, 1992). The boundaries for the new stations may need slight adjustments to account for different site characteristics; however, initial results appear acceptable. Once sufficient data has been collected at a new site, a new set of boundaries may be established. 


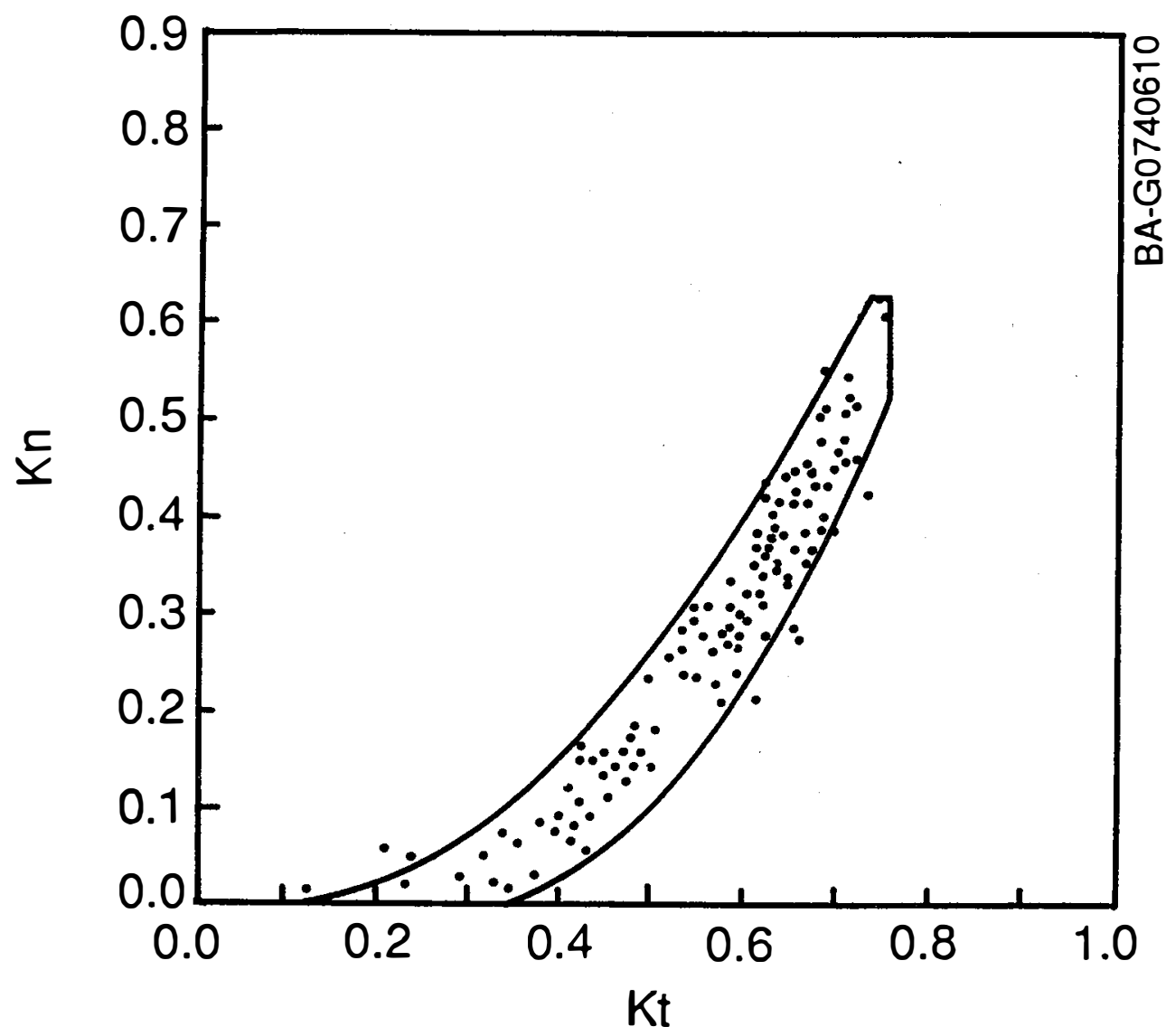

Figure 1. SERI QC data boundaries for two-element quality assessment

In Figure 1, the direct normal transmittance is plotted against global horizontal transmittance. The lower boundary illustrates that with increasing cloud cover, direct normal radiation decreases more rapidly than global horizontal radiation. Consequently, data for cloudy skies are grouped toward the lower boundary. Clear sky data reside near the upper boundary. For some seldom occurring conditions, data depicting real conditions may reside outside the boundaries and be flagged as bad data. For example, if the sun is near the edge of a cloud, some of the sun's rays can be reflected off the edge of the cloud and increase the global horizontal radiation and $\mathrm{K}_{\mathrm{t}}$ without affecting the direct normal radiation and $\mathrm{K}_{\mathbf{n}}$. This shifts the data point to the right in Figure 1, and it may be to the right of the lower boundary if $K_{t}$ is large enough.

After all SERI QC tests are completed, flags are assigned to the data according to the convention listed in Table 1. 
Table 1. Flagging Convention for Global Horizontal, Diffuse Horizontal, and Direct Normal Solar Radiation

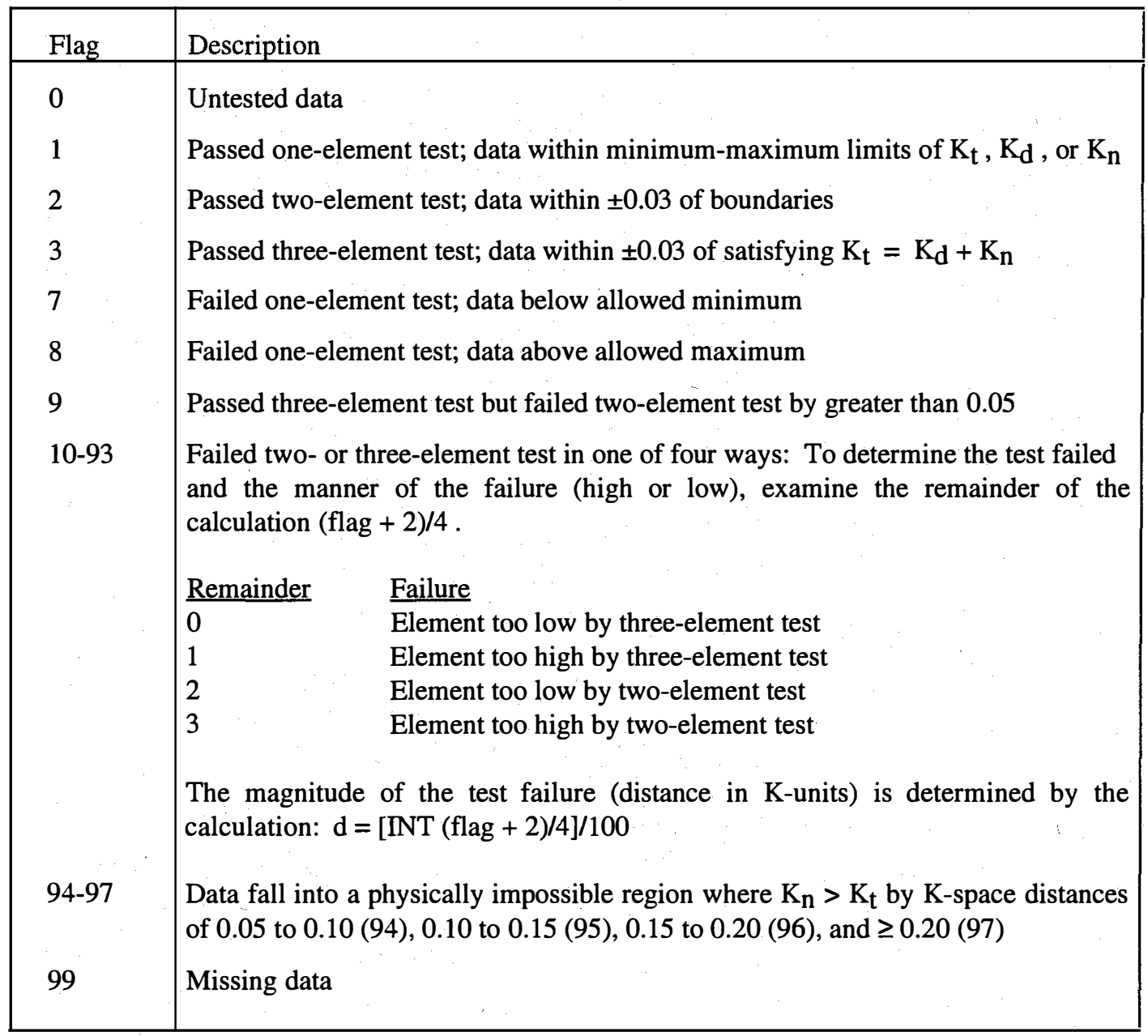

\subsection{Quality Assessment for Dry-Bulb Temperature Data}

For dry-bulb temperature data, quality assessment is performed using one-element tests to see if data reside between minimum and maximum values. The minimum and maximum values are the record monthly highs and lows, presented by Marion and Wilcox (1994) for a nearby location. Flags are assigned to the data according to the convention listed in Table 2.

Table 2. Flagging Convention for Dry-Bulb Temperature

\begin{tabular}{|l|l|}
\hline Flag & Description \\
\hline 1 & Passed one-element test; temperature between record low and high, by month \\
7 & Failed one-element test; temperature less than record low, by month \\
8 & Failed one-element test; temperature greater than record high, by month \\
99 & Missing data \\
\hline
\end{tabular}




\subsection{Data and Summary Information}

After the data are quality assessed, they are formatted into hourly data sets for each month. A one-page summary for each month provides a graph showing average diurnal profiles and tables listing pertinent solar radiation and dry-bulb temperature statistics. The data sets and summary information are for use by both NREL and the industry participant.

\subsection{Hourly Data Sets}

Data and their quality assessment flags are organized in monthly station files with the file extension .QAD to signify that the file contains quality assessed data. The eight-character file prefix identifies the station and the month and year. For example, SACR9403.QAD contains quality assessed hourly data for Sacramento, California, for March 1994. The Sacramento station is identified in the file name by a unique four-character descriptor.

Figure 2 shows the contents of a quality-assessed data file. The first line identifies the station and contains: the four-character station identifier; the city and state; the time zone in number of hours by which the local standard time lags behind Universal Time (EST = -5, CST = -6, MST = -7, PST = -8); latitude $\left({ }^{\circ}\right)$; longitude $\left(^{\circ}\right)$; and elevation $(\mathrm{m})$.

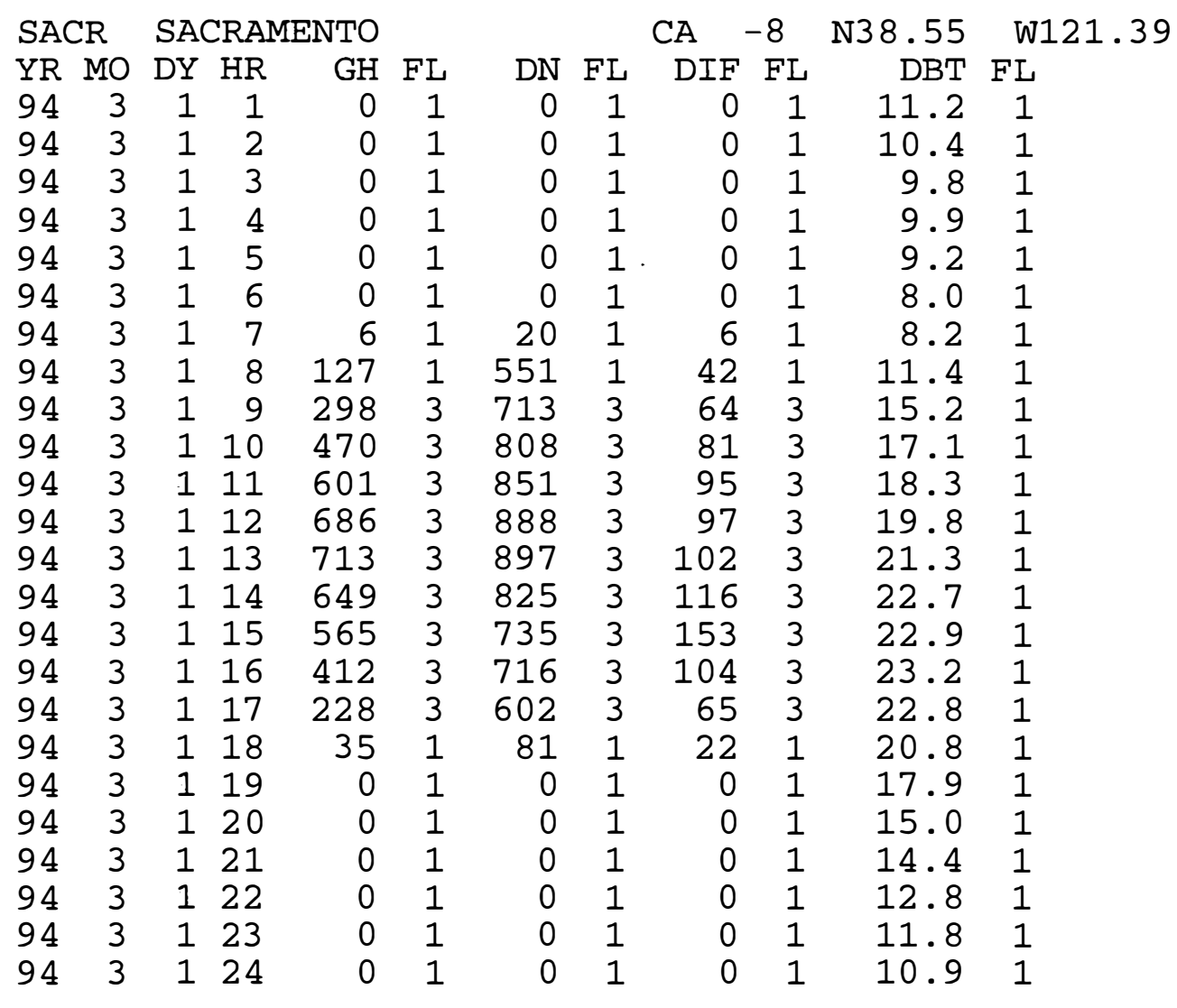

Figure 2. Sample format of data file SACR9403.QAD 
The second line in the data file consists of header abbreviations to identify the columns of data that begin with line three. The time and data elements are presented in the order: year (YR), month (MO), day (DY), hour (HR), global horizontal radiation (GH), direct normal radiation (DN), diffuse horizontal radiation (DIF), and dry-bulb temperature (DBT). Quality assessment flags (FL) follow each of the data elements. Solar radiation units are $\mathrm{Wh} / \mathrm{m}^{2}$ and dry-bulb temperature units are degrees Centigrade. Solar radiation data are integrated over the preceding hour, and dry-bulb temperature data are averaged over the preceding hour. (Data for hour 11 contains data measured from 10:00 a.m. to 11:00 a.m.)

\subsection{Monthly Summaries}

A one-page summary for each month provides a graph showing average diurnal profiles and tables listing pertinent solar radiation and dry-bulb temperature statistics. Depending on the needs of the industry participant, solar radiation diurnal profiles and monthly-averages for certain collectors are modeled using the measured data as input, and are included in the monthly summary.

Temperature statistics include the average monthly dry-bulb temperature, the average daily minimum and maximum dry-bulb temperature, and the minimum and maximum dry-bulb temperature recorded for the month. Data recovery and quality assessment information are given by listing the percentage of solar radiation and dry-bulb temperature data missing, the percentage of solar radiation data greater than $5 \%$ from the SERI QC boundaries, and the percentage of dry-bulb temperature data below the lower limit or above the upper limit. Percentages are based on the total number of hours in the month.

Figure 3 shows an example of a one-page summary. The summary data calculations only use solar radiation data that are within 5\% of the SERI QC boundaries. These data have quality assessment flags 1-3 and 10-21. 


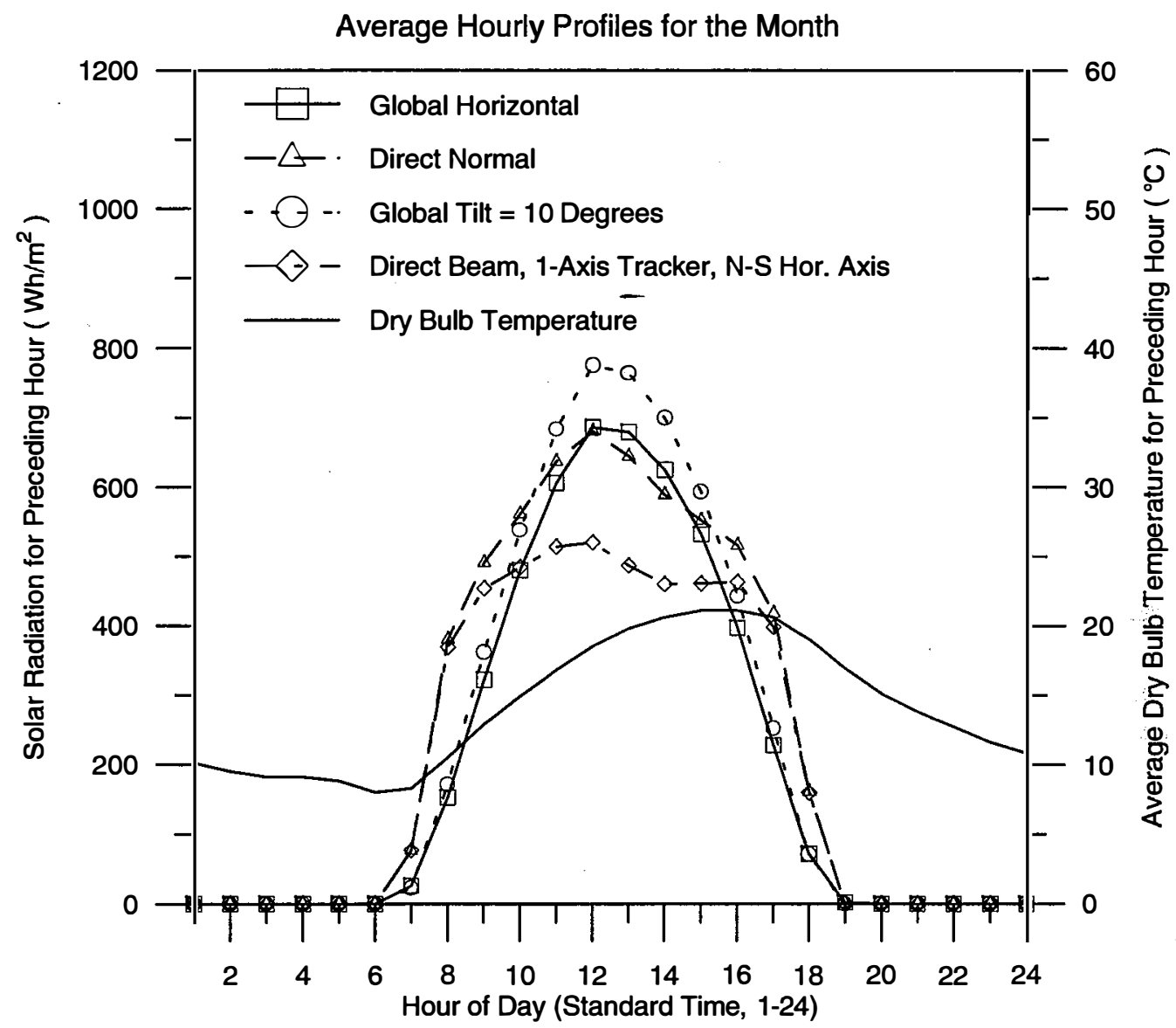

Monthly Solar Radiation ( $\mathrm{kWh} / \mathrm{m}^{2} /$ day)

Global horizontal

Direct normal

Global south-facing for a $10^{\circ}$ tilt from horizontal (modeled)

Direct beam for 1-axis tracker with N-S horizontal axis (modeled)

Monthly Dry-Bulb Temperature Statistics

Average $\left({ }^{\circ} \mathrm{C}\right)$

Average daily minimum $\left({ }^{\circ} \mathrm{C}\right)$

Average daily maximum $\left({ }^{\circ} \mathrm{C}\right)$

Data Recovery and Quality Assessment Information

Solar radiation data missing (\%)

Solar radiation data $>5 \%$ from SERI QC boundaries $(\%)$ 


\subsection{References}

Marion, W.; Wilcox, S. (1994). Solar Radiation Data Manual for Flat-Plate and Concentrating Collectors. NREL/TP-463-5607. Golden, CO: National Renewable Energy Laboratory.

NREL. (1993). User's Manual for SERI QC Software-Assessing the Quality of Solar Radiation Data. NREL/TP-463-5608. Golden, CO: National Renewable Energy Laboratory.

NSRDB-Volume 1. (1992). User's Manual-National Solar Radiation Data Base (1961- 1990). Version 1.0. Asheville, NC: National Climatic Data Center.

Stoffel, T.; Riordan, C.; Bigger, C. (1992). Evaluation of Solar Radiation Measurement Systems: EPRI/NREL Final Test Report. NREL/TP-463-4771. Golden, CO: National Renewable Energy Laboratory. 
Appendix A

Equipment Installation 


$$
\text { Modified Instructions by NREL 9/14/93 }
$$

\title{
Rotating Shadowband Pyranometer
}

\author{
Ascension Technology, Inc. \\ P.O. Box 314 \\ Lincoln Center, MA 01773 USA \\ Telephone 617-890-8844 • Facsimile 617-890-2050
}

\section{Installation Instructions}

The Ascension Technology Rotating Shadowband Pyranometer (RSP) represents a breakthrough in simplifying the measurement of direct normal and global diffuse solar energy resources. The instrument is lower in cost, easier to install and easier to operate than either manually adjusted shadowbands or pyrheliometers that are needed to acquire similar data. Only a few set-up steps are required. These instructions are for installations in the northern hemisphere. For locations in the southern hemisphere, all compass direction references should be reversed.

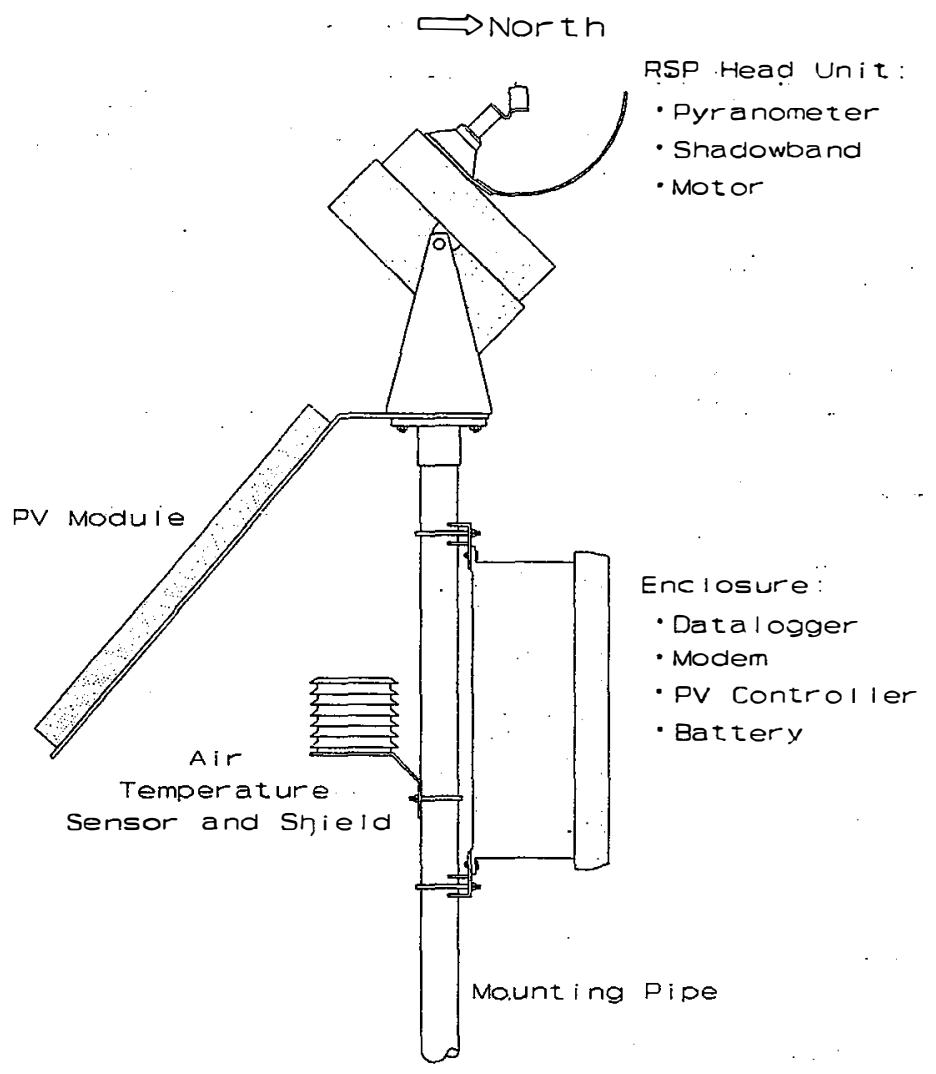




\section{Step 1: Site Selection and Preparation}

Situate the RSP in a location with wide open southern exposure which is as free as possible from shading by trees, buildings and mountains in the directions of sunrise and sunset throughout the year. The sensor should be higher than nearby reflective surfaces. Even if these surfaces never block the direct path of light, the scattering of light from these surfaces will increase the amount of diffuse light recorded by the RSP. Once a site has been selected, it is necessary to determine the latitude and longitude in order to program the datalogger correctly. If you are unable to determine these coordinates, please consult Asonsion NREL. unfasten

Open the RSP shipping box and untalat stapping. The major components of the system are the enclosure, head unit/PV panel assembly, mounting pipe and plywood base. The small plywood piece is for shipping purposes only. The 12 Volt battery used by the system is shipped separately, from NREL.

Open the enclosure and remove the gill shield, base flange and plastic bag of miscellaneous parts. This bag contains 11 items:

1. Hex key for tightening flanges onto pipe

2. Miniature slotted screwdriver for CR10 wiring panel

3. Miniature hex key screwdriver for levelling sensor

4. Bubble level for levelling sensor

5. Box of fuses: 2 each of 4,5 and 7 amps

8. Cotton balls for cleaning sensor

9. 2 pieces of foam paper for concealment of battery terminals

10. Brass grounding clamp

11. Black tie wraps for securing wires/cables, etc.

Save the box and all shipping material
for the return of the unit to WREL
at the end of the loan period

A $1 \frac{1}{4}$-inch $(3.18 \mathrm{~cm})$ diameter aluminum pipe is provided for mounting the solar monitoring station instruments. The RSP head unit, datalogger enclosure, solar panel and gill shield temperature probe are all mounted to this pipe.

The pipe can be installed in a number of ways. An effective approach is to bolt the bottom flange to a ballasted wooden platform or to any suitable rigid horizontal surface. Hardware for this setup has been provided: the bottom flange can be found inside the enclosure and the plywood mounting base is in the shipping container. Cement blocks 
should be used as ballast for the base.

Another option is to bolt two short sections of uni-strut rail near the top of a masonry wall and clamp the pipe to these rails. A third approach is to clamp the pipe to existing steel guard-rail supports using stainless steel hose clamps. Regardless of how the pipe is mounted, it need only be rigid and vertical. The pipe should be secure enough that severe winds will not displace or shake the unit.

\section{Step 3: Mount the Enclosure}

U-bolts on the enclosure mounting brackets are used to secure the enclosure to the pipe. Mount the enclosure on the north side of the pipe if possible, placing it approximately 5 inches from the top of the pipe. Uncoil the RSP connector and temperature probe and send them down through the pass-through located on the bottom panel of the enclosure (The RSP circular plastic 9-pin connector plug must be sent through first).

$$
\begin{gathered}
\text { Check fasteners in enclosure } \\
\text { to ensure they did not loosen } \\
\text { during shipping }
\end{gathered}
$$

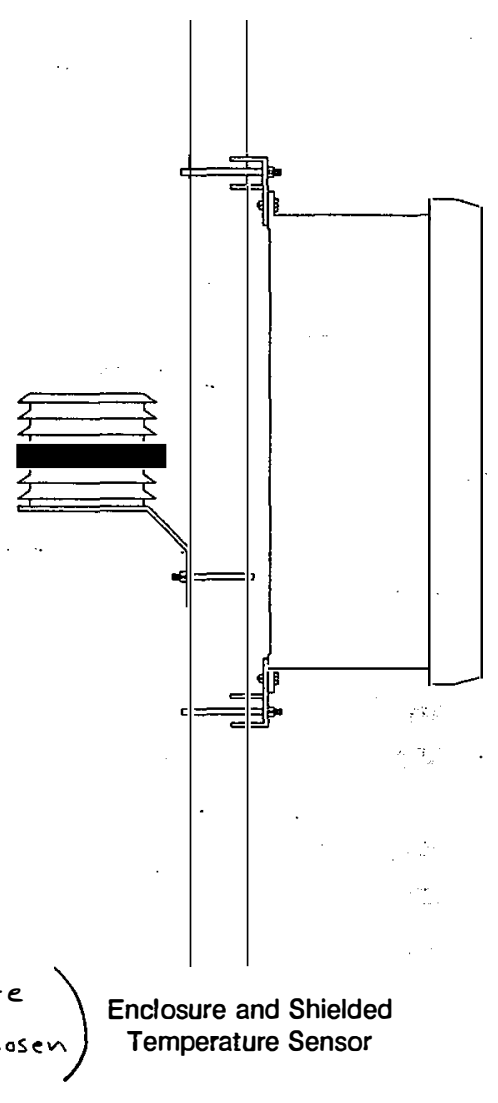

Step 4: Mount the Gill Shield and Temperature Probe

Attach the gill shield to the mounting pipe at the center of the enclosure. If possible, orient the shield so that it faces directly away from the enclosure (south). Insert the temperature probe into the gill shield. Gently tighten the clamp onto the bottom 1/2" of the shrink wrap. The clamp should hold the cable snugly but not so tightly that the cable is pinched excessively. 
Step 5: Mount the Photovoltaic Module and RSP Head Unit

Place the head unit/panel assembly onto the pipe and tighten the flange set $\Longrightarrow$ North screws. (If the unit was shipped) unassembled, the PV module bracket should be fastened between the RSP mounting yoke and the aluminum flange. Note the requirements for panel and RSP orientation given in the next paragraph.) The PV panel is provided with a cable terminating in a 2-pin connector. Lead the Prevents damaging connector up through the enclosure passthrough but do not connect it to its mating receptacle. PV power must not be charge applied until after the battery has been controller connected (step 8). Plug the RSP connector into the receptacle on the head unit.

Face the PV panel into southern sky

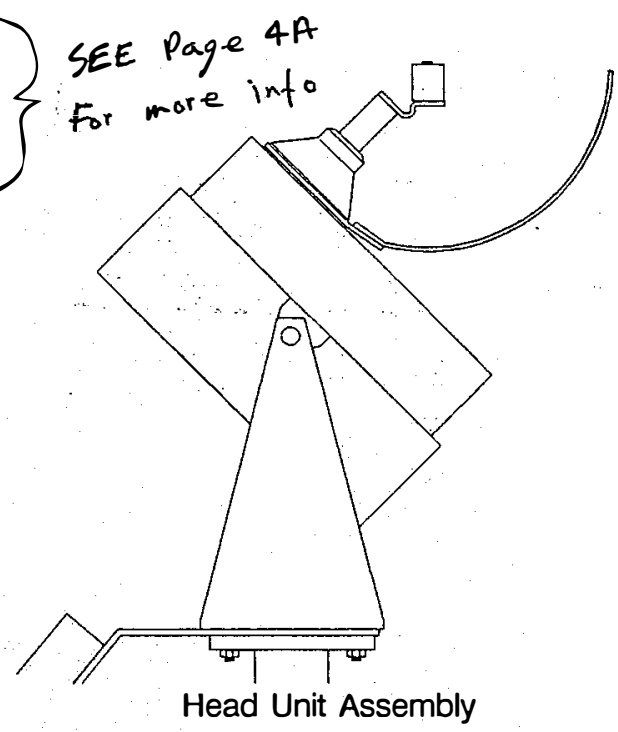

and the RSP head unit north as seen in figure 3 . The alignment of the RSP should be within \pm 5 degrees of true, not magnetic north. If you are using a compass, be sure to account for the local magnetic declination. Using a compass is inadvisable if metal structures exist nearby. In this event, consult with Aseension E Teehnology for a list of solar noon times for the site so that orientation may be achieved in this manner.

Step 6: Level the RSP Sensor $\leftarrow$ Essential for proper operation!
Remove protective red cover from pyranometer

Level RSP sensor by rotating the RSP about its mounting bracket axis and turning the small cylinder on which the sensor is mounted. The cylinder is loosened by using the hex key driver to partially unscrew the set screw located in the black, funnel-shaped base. Place and center the bubble level directly on the sensor and adjust the head unit along both axes until the bubble is within the center circle. The levelness will not be accurate unless the level is centered on the sensor. Be sure to re-check and maintain levelness as the cylinder set screw and bracket bolts are tightened. Remove bubble level when done leveling. 
INSTALLATION INSTRUCTIONS FOR PV PANEL BRACKET BRACE RETROFIT

The existing PV panel bracket is not supported at the bottom, causing undue flexing of the bracket and in extreme cases fatigue failures at the bend in the bracket. This retrofit is designed to give rigidity to the bracket and prevent these fatigue failures.

1) Remove the mounting bolt at the bottom of the existing PV panel bracket.

2) Approximate the horizontal line extending from the mounting hole described in step 1, back to the mounting pole. Place the ubolt around the mounting pole at that position. (If other hardware is in the way such as the temperature sensor gill shield or one of the mounting brackets for the CR10 enclosure, move these-items so that the brace will fit.)

3) Put brace in place along the horizontal line described in step 2 ; and finger tighten nuts on u-bolt.

4). Replace bolt in bottom of panel, threading it through:

a) Module rail

b) Mounting bracket

c) Retrofit brace

Tighten three nuts.

Note: The u-bolts are not supplied with star,locking, or flat washers and they are not necessary for proper installation. Replace the panel bolt with the existing washers.

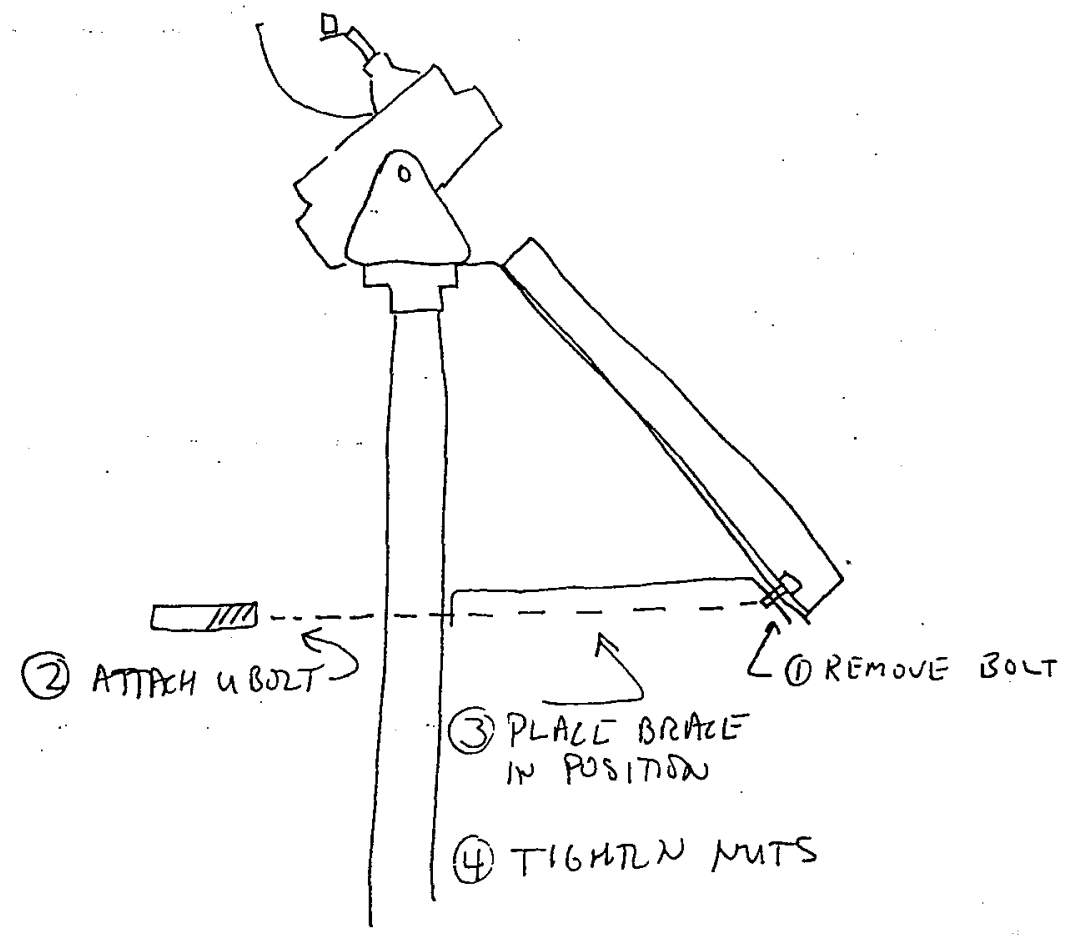


Pass the telephone line up through the enclosure pass-through and connect it to the terminals of the telephone line surge suppressor mounted at the right end of the CR10 datalogger. If possible it is advisable to match the tip and ring lines with the modem ports. If the lines are striped, ring lines are commonly a dark color with light stripes; tip lines will have the corresponding light color with dark stripes. Other common tip/ring pairs are green/red and black/yellow.

Step 8: Install the Battery

$$
\begin{aligned}
& \text { Take all necessary precautions! Remove } \\
& \text { rings and other jewelry- }
\end{aligned}
$$

Use the foam paper ${ }^{1}$ and a tie-wrap to cover the negative battery terminal. With the positive terminal on the left and the negative terminal on the right, carefully place the battery inside the enclosure. This will prevent the terminals from touching the datalogger. Each of the power leads from the datalogger are equipped with 1/4-20 bolts and nuts. First, connect the positive lead (the one with the 3 in-line fuses and the orange wire) to the battery positive terminal on the left. Tie-wrap the second piece of foam paper around the entire connection to the positive terminal in order to avoid an inadvertent short-circuit. Remove the foam paper on the negative terminal, connect the negative lead to its battery terminal and replace the foam paper. The battery negative and all metal surfaces within the enclosure will be at ground potential once this connection is made. As there is no "on-off" switch for the system there may be a small spark when the negative lead touches the terminal due to capacitor charging.

The three fused connections to the positive battery terminal are the head unit, charge controller and datalogger (4,10,5 amps). The negative line is also fused ( $7 \mathrm{amps})$.

Be careful not to reverse leads and damage datalogger.

\section{Step 9: Grounding}

In order to protect the electronics in the RSP system the unit must be grounded properly. Mount the brass grounding clamp onto the pipe just below the enclosure. Run a grounding line of at least 14 AWG wire (not provided) from the aluminum grounding lug on the side of the enclosure to the brass clamp and then out to a solid ground. Most roofs have grounding nets; if the installation is on the ground a copper grounding rod is sufficient. $\rightarrow$ Make' sure ground connections are tight. $<$

\footnotetext{
${ }^{1}$ If the foam paper has been lost or was not provided, use any means to electrically insulate the battery terminals. Electrical tape is a suggested alternative. 
Finishing the Installation

Once the battery is connected and the unit is grounded, mate the PV panel connectors inside the enclosure. Tie-wrap the PV, RSP head unit and temperature probe cables to the pipe, leading them securely down to the enclosure pass-through. The RSP connector cable should be secured such that it provides strain relief for the connection to the head unit (i.e. no downward force on the plug). If the length is available, form a "drip loop" with the wires before they enter the enclosure. Store extra length in any of the lines in the space to the left of the battery inside the enclosure. Use the foam paper wrapped around the gill shield for shipment to plug the pass-through from the inside once all wiring is completed.

\section{Commencement of Solar Monitoring}

$$
\text { BILL MARION @ NREL at 303/275-4620 }
$$

Call Asconsion-Technology at-617-890-8844 to report on the installation proceedings. We will need the number of the phone line in order to program the datalogger. During daytime operation the RSP makes a full rotation once per minute. During nighttime hours the RSP will rotate once every half hour. If possible? is strongly recommended that the sensor be cleaned twice per week Cotton balls and distilled water are sufficient for cleaning.

$$
\begin{aligned}
& \text { (1) Be careful so that the shadowband does not strike you when } \\
& \text { it rotates. The motor is strong and you could be injured. If } \\
& \text { the sensor is covered, such as by the bubble level when } \\
& \text { checking the sensor level, the datalogger does not rotate } \\
& \text { the shadowband. } \\
& \text { (2) Complete the maintenance and maintenance log as instructed } \\
& \text { on the maintenonce log sheet }
\end{aligned}
$$




\section{Appendix B}

Sample Maintenance \& Operation Log Sheet 


\section{Maintenance \& Operation Log Sheet}

Site: Bergquam Energy

8611 Folsom Blvd.

Sacramento, CA 95826

(916)383-9425
Lat: $\quad 38^{\circ} 32^{\prime} 50^{\prime \prime}$

Long: $121^{\circ} 23^{\prime} 08^{\prime \prime}$

Elev: $12 \mathrm{~m}$
System ID: \#55, DOE 120041

Pyranometer: LI-COR PY17940

Perform maintenance and complete the form below per the instructions on the back of this page.

\begin{tabular}{|c|c|c|c|c|c|c|}
\hline Date & $\begin{array}{c}\text { Local } \\
\text { Standard } \\
\text { Time } \\
\end{array}$ & $\begin{array}{c}\text { Sensor } \\
\text { Cleaned }\end{array}$ & $\begin{array}{c}\text { Shadowband } \\
\text { Rotation } \\
\text { Checked } \\
\end{array}$ & $\begin{array}{c}\text { Sensor } \\
\text { Level } \\
\text { Checked } \\
\end{array}$ & $\begin{array}{c}\text { Sensor } \\
\text { Level } \\
\text { Adjusted } \\
\end{array}$ & Notes \\
\hline & & & & & & \\
\hline & & & & & & \\
\hline & & & & & & \\
\hline & & & & & & \\
\hline & & & & & & \\
\hline & & & & & & \\
\hline & & & & & & \\
\hline & & & & & & \\
\hline & & & & & & \\
\hline & & & & & & \\
\hline & & & & & & \\
\hline & & & & & & \\
\hline & & & & & & \\
\hline & & & & & & \\
\hline & & & & & & \\
\hline & & & & & & \\
\hline & & & & & & \\
\hline
\end{tabular}




\section{Maintenance Instructions}

Maintenance of the rotating shadowband radiometer consists of keeping the sensor clean, ensuring that the sensor remains level, and checking to see that the shadowband rotates. The best time for maintenance is first thing in the morning so as not to interfere with readings during the middle of the day when solar radiation is the highest. Both the top and sides of the white "button" portion of the pyranometer should be cleaned twice a week using a cotton ball and distilled water. If there is noticeable dirt buildup between cleanings, clean more frequently.

The pyranometer should be checked for levelness with the bubble level, and then adjusted if needed. The bubble should be within the black circle on the level. This check should be made more frequently at first until you have confidence that the support structure is not moving, at which point checks every two weeks are probably sufficient. Be careful that the shadowband does not strike you when you place the level on top of the sensor. Once the level is in place, the shadowband will not rotate because the data logger thinks it is dark. With the level removed, the shadowband should rotate at the rate of once a minute as long as it is not severely overcast or nighttime.

When making your maintenance checks, fill out the maintenance and operation log sheet on the back of this page by entering the date and time (local standard time, not daylight savings, please) and putting check marks in the appropriate boxes. A place for "notes" is included so you can make entries for any equipment problems, for unusual or special circumstances that might affect the resource information, or for other events that may be of particular importance. For example, bird droppings on the sensor would decrease the measured radiation much more so than normal soiling. A day without clouds might also be worth noting for your future analysis of system performance. Feel free to add information to the log sheet that is of interest to you.

The maintenance you perform is the only way we can ensure that the data collected is high quality. Small changes in sensor output from sensor soiling and unlevelness cannot be detected after the data are measured.

At the end of each month, FAX the maintenance log sheet to Bill Marion at 303/275-4611. You do not need to use a new log sheet for each month; you may continue to use the same log sheet until it is full, but remember to FAX it to NREL at the end of each month. Keep the originals for your records.

For problems requiring immediate attention, call Bill Marion at 303/275-4620, or Russell Hewett at $303 / 275-3663$. 


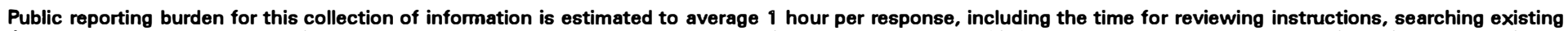

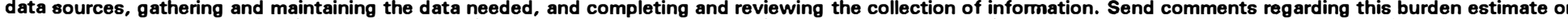

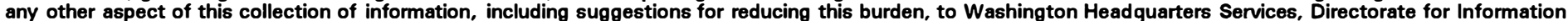

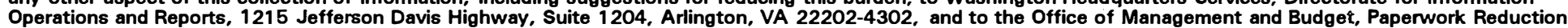
Project (0704-0188), Washington, DC 20503.
1. AGENCY USE ONLY (Leave blank)
2. REPORT DATE.
3. REPORT TYPE AND DATES COVERED June 1994
Technical report

4. TITLE AND SUBTITLE

Site-Specific Solar Resource Measurements for Industrial Solar Applications

5. FUNDING NUMBERS

SI414010

6. AUTHOR(S)

William Marion

7. PERFORMING ORGANIZATION NAME(S) AND ADDRESS(ES)

National Renewable Energy Laboratory

1617 Cole Boulevard

8. PERFORMING ORGANIZATION

REPORT NUMBER

Golden, CO 80401-3393

TP-463-6689

9. SPONSORING/MONITORING AGENCY NAME(S) AND ADDRESS(ES)

U.S. Department of Energy

1000 Independence Ave., SW

Washington, DC 20585 AGENCY REPORT NUMBER

11. SUPPLEMENTARY NOTES

12a. DISTRIBUTION/AVAILABILITY STATEMENT National Technical Information Service U.S. Department of Commerce 5285 Port Royal Road

Springfield, VA 22161 12b. DISTRIBUTION CODE

UC 233, 310

13. ABSTRACT (Maximum 200 words)

The solar industry can borrow solar radiation measuring equipment from the National Renewable Energy Laboratory (NREL) as part of NREL's Solar Industrial Program. This program provides assistance to qualified parties in quantifying the solar radiation resource at prospective sites to reduce the risks of deploying industrial solar energy systems. Up-to-date solar radiation measurements permit comparisons of fresh data with existing data to verify established data bases and also provide data based on actual measurements instead of on less accurate models. This report outlines the responsibilities and obligations of NREL and the solar industry participant. It also describes the equipment for measuring solar radiation, the data quality assessment procedures, and the format of the data provided.

14. SUBJECT TERMS

solar radiation; solar resource assessment; solar industrial

15. NUMBER OF PAGES

32

16. PRICE CODE

A03

\begin{tabular}{l|l|l|l} 
17. SECURITY CLASSIFICATION & $\begin{array}{l}\text { 18. SECURITY CLASSIFICATION } \\
\text { OF THIS PAGE } \\
\text { Of REPORT } \\
\text { unclassified }\end{array}$ & $\begin{array}{l}\text { 19. SECURITY CLASSIFICATION } \\
\text { OF ABSTRACT } \\
\text { unclassified }\end{array}$ & $\begin{array}{c}\text { 20. LIMITATION OF ABSTRACT } \\
\text { UL }\end{array}$
\end{tabular}

NSN 7540-01-280-5500

Standard Form 298 (Rev. 2-89)

Prescribed by ANSI Std. Z39-18 